\title{
Economía municipal en el Guanajuato de las reformas borbónicas: instantánea de un quinquenio (1788-1792)
}

José Luis Caño Ortigosa

Universidad de Cádiz (España) 



\title{
Economía municipal en el Guanajuato de las reformas borbónicas: instantánea de un quinquenio (1788-1792)
}

\section{Municipal treasuries in colonial America: Bourbon Guanajuato (1788-1792)}

\author{
José Luis Caño Ortigosa \\ Universidad de Cádiz (España) \\ joseluis.ortigosa@uca.es
}

Fecha de recepción: 11 de diciembre de 2020

Fecha de aceptación: 23 de abril de 2021

\section{Resumen}

En este trabajo avanzamos en el todavía escaso conocimiento de las haciendas municipales de las poblaciones de la América colonial. Utilizando como muestra los ingresos y gastos del ayuntamiento de Guanajuato en un lustro de fines del siglo XVIII, puede conocerse mejor la capacidad recaudatoria de los municipios y el destino que se le daba a esas cantidades obtenidas. Asimismo, se pueden entender mucho mejor los cambios que se fueron produciendo en las rentas de los municipios coloniales con la implantación de las nuevas normas derivadas de las reformas borbónicas.

Palabras clave: Cuentas municipales; Hacienda; Cabildos; Guanajuato; Propios y Arbitrios

\begin{abstract}
This article supplements the scarce knowledge of fiscal changes that took place in the municipal treasuries in Colonial Spanish America. By looking at the movement of tax money in Guanajuato's city hall, we can better understand the extent of its tax-collecting efforts and expenditures. We also discover how the implementation of new rules imposed by the Bourbonic reforms affected the income of the city's government.
\end{abstract}

Key words: Municipal accounts; Finance office; Town Council; Spanish Indias; Economic History 
$\underline{\text { Economía municipal en el Guanajuato de las reformas borbónicas... - J.L. Caño }}$

\section{INTRODUGGIÓN}

Desde fines del siglo XX, el estudio de las haciendas municipales en la España moderna ha experimentado un notable desarrollo, como lo evidencian algunos trabajos publicados durante este tiempo. ${ }^{1}$ Mucha menos atención ha disfrutado la misma temática para los municipios coloniales, si bien han comenzado a aparecer estudios que están permitiendo importantes avances en su conocimiento. ${ }^{2}$ Uno de los municipios indianos cuyas rentas públicas han empezado a ser investigadas es Guanajuato, al que nosotros ya hemos dedicado varios trabajos, esencialmente para el período previo a la aplicación de las Reformas Borbónicas en la segunda mitad del siglo XVIII (Caño Ortigosa, 2020, pp. 1-39).

De hecho, tal y como adelantábamos brevemente en las conclusiones de ese trabajo citado, las reformas se impusieron para conseguir un mayor control y mejor gestión de los propios y arbitrios por parte de las distintas autoridades. Como intentaremos demostrar ahora, en el caso de Guanajuato se implantaron para dar respuesta a la creciente complejidad que con el paso del tiempo fueron adquiriendo sus rentas, dentro de la dinámica de fuerte desarrollo económico y demográfico que estaba experimentando la población en aquellos años (Caño Ortigosa, 2011, pp. 3180 y Caño Ortigosa y Lara Valdés, 2020, pp. 63-89).

De hecho, ya dos décadas antes del informe de 1793 que en este trabajo utilizaremos como principal documento de referencia, Gálvez había tomado la decisión de reformar la administración de las rentas municipales guanajuatenses, modificando los usos que se venían practicando desde 1732 y que resultaban obsoletos ante esa nueva dinámica de crecimiento y desarrollo. Entre otras cosas, Gálvez ordenó cambiar la manera de ordenar y presentar las cuentas, instruyendo un formulario que las separaba en tres ramos. Con ello se adaptaba a las categorías dictadas por el Tribunal de Cuentas de México en 1785 (Sánchez Santiró, 2015). Es decir, los ramos de "Real Hacienda afectos a cargas comunes, los de Real Hacienda afectos a cargas o destinos particulares y en la tercera clase los Ramos ajenos de Real Hacienda". ${ }^{3}$ Todas las partidas que pudieran incluirse en ese tipo de apartados, como veremos más adelante con detalle, debían contabilizarse y en el caso de Guanajuato se incluían los impuestos a los granos y su almacenaje en la alhóndiga municipal, el importe de las licencias de los puestos de las calles, el suelo municipal que se

1 Redondo Veintemillas, (1977), pp. 108-140. Ruiz Martín, (1978), pp. 37-47. Bernal, (1978), pp. 285-312. Pardos Marunez, (1984), pp. 599-612. Ferrero Migó, (1987). Hoz García, (1988), pp. 77-101. Quintana Toret, (1989), pp. 81-10. Salas Ausens, (1992), pp. 9-66. Bernardo Ares, (1993). Giménez Chornet, (1995), pp. 243-247. López Nevot, (1995) pp. 749-805. García García, (1996). Ladero Quesada, (1997), pp. 7-71. Gutiérrez Alonso (1997), pp. 187-211. Martínez Ruiz, (1992) у (2000), pp. 863-877. Mateos Royo, (2003), pp. 51-77.

2 Ensinck, (1990). Jáuregui, (1999). Sánchez de Tagle, (2010), pp. 164-224 y (2014). Sanchez Santiró (2013). Bertrand (2018), pp. 141-156. Celaya Nández, Yovana (2018), pp. 157-173. Suárez Grimón, (2005).

3 Archivo General de la Nación (AGN en adelante), Archivo Histórico de Hacienda, vol. 1183. 
vendía para hacer nuevas casas, los sobrantes de los festejos, las corridas de toros anuales, los impuestos a los vinos y aguardientes, los nuevos impuestos creados para el mantenimiento de las milicias y la creación de infraestructuras de comunicaciones en la ciudad. No obstante, la complejidad de las rentas guanajuatenses, o un intento por ordenarlas más claramente, evitó su presentación formal en esos tres ramos indicados.

En cambio, para registrar todo, el responsable de la administración de los propios y arbitrios guanajuatenses sí estaba obligado a hacerlo en diecisiete libros distintos, cuatro para los fieles de la alhóndiga y el de entradas del poblado de Marfil y los restantes para las alhondiguillas de los barrios y de las minas. Uno de esos libros debía ser específico para los impuestos al alcohol y en él debía participar el contador de la aduana, mientras que en otro debían aparecer los gastos de los empedrados de las calles, reparaciones y obras. Los toros, los puestos en alquiler en la calle y la limpieza anual del río y de las presas no necesitaban de libros específicos. En los casos de las corridas de toros, por ejemplo, se remataban anualmente al mejor postor, necesitando sólo anotar la partida de ingreso de dichas pujas. Otro de los libros debía reflejar el salario de los capitulares y de los trabajadores del ayuntamiento, en el orden especificado por el visitador. Finalmente, después de indicar al procurador general que debía primar el pago de los censos contraídos por el ayuntamiento y la finalización de los préstamos sobre cualquier otro tipo de gastos, se estipuló un estipendio a favor del capitular del $2 \%$ del total de la cantidad sumada cada año en concepto de ingresos. ${ }^{4}$

En definitiva, se trataba de acatar el nuevo reglamento que para las rentas municipales de las distintas poblaciones del virreinato había diseñado Gálvez, y que integraba a la institución de la Contaduría específica de propios y arbitrios (Celaya Nández, 2016, pp. 6-8). Un reglamento que, sabemos ya, también tuvo sus efectos en poblaciones como Orizaba, Querétaro y Puebla (Bertrand, 2018, pp. 141-156 y Celaya Nández, 2018, pp. 157-173). Esta nueva dinámica contable, más depurada, ordenada y fiscalizable se mantuvo en Guanajuato a partir de entonces, con el beneplácito de los virreyes, quienes, a su vez, eran los responsables de autorizar cada nueva partida de gastos y de impuestos que se pretendieran realizar. En especial, los virreyes se mantuvieron atentos a los llamados gastos extraordinarios, que por su propia naturaleza eran más difíciles de controlar y solían suponer elevadas sumas de dinero. Ello fue debido, principalmente, a que ese tipo de gasto solía dar respuesta a urgencias sobrevenidas, en ocasiones de carácter catastrófico como las frecuentes inundaciones que se producían en Guanajuato e, incluso, algunos terremotos. Ejemplo concreto de ello fue la elevada suma dedicada en 1783 para la limpieza del cauce del río que atraviesa la urbe y que, taponado por los escombros, basuras y atierres naturales, provocó inundaciones que costaron la vida a numerosas personas, además

4 Formulario de la cuenta general que debe llevar cada año el procurador general de Guanajuato, 31 de diciembre de 1770. AGN, Ayuntamientos, 134, exp. 5. 
Economía municipal en el Guanajuato de las reformas borbónicas... - J.L. Caño

de cuantiosos daños materiales. Ya en ese momento, además de al regidor designado como cabal de la obra, también se le indicó expresamente al procurador general del concejo, responsable de las cuentas municipales, que llevara fiel contabilidad de cuanto se hiciere. ${ }^{5}$

Toda una serie de gastos que nunca dejaron de aumentar en la ciudad, motivado por su constante desarrollo al calor de la cada vez más rica explotación de sus minas durante todo el siglo XVIII. Pero también aumentaron, por ese espectacular crecimiento, las posibilidades de recaudación de los impuestos municipales, principalmente los arbitrios ordinarios y los extraordinarios o temporales. Más aún, con el beneplácito de las autoridades imperiales, materializado en la Instrucción de 1768 y en la Ordenanza de Intendentes de 1786, que otorgaron a los ayuntamientos un recurso institucional, político y jurisdiccional en sus territorios para imponer más gravámenes a sus vecinos, siendo buen ejemplo de ese fenómeno la ciudad de Veracruz (Celaya Nández, 2014, pp. 37-59). Así, eran especialmente cuantiosos los arbitrios obtenidos por la fiscalización de la entrada y salida de productos, del almacenaje de granos, así como del trato y el consumo de bienes y alimentos. En este sentido, con las licencias otorgadas a la ciudad en la segunda mitad de la centuria para el cobro de la sisa sobre los vinos y aguardientes, además de la ampliación de lo cobrado en concepto de entrada, alhondigaje y venta de granos y harinas, gracias al denominado nuevo impuesto, el municipio vio multiplicadas sus posibilidades financieras. Hasta tal punto crecieron que se hizo frecuente el superávit anual a fines de siglo, incluso después de haber aumentado también significativamente sus gastos. ${ }^{6}$

En realidad, en este fenómeno histórico, el caso guanajuatense no fue más que otro ejemplo añadido entre los municipios españoles, tanto metropolitanos como indianos, en los que se implantaron un gran número de nuevos arbitrios de ese tipo, entre los que destacó el impuesto de la sisa como se demostró para el caso novohispano en poblaciones como México, Pátzcuaro, Oaxaca y Valladolid (Celaya Nández, 2014, p. 42). Con ellos, consiguieron sanear las más que deficitarias rentas de propios y arbitrios la mayor parte de las localidades del imperio. Llegaron a ser tan importantes para las distintas ciudades y villas estos ingresos extraordinarios que, en la mayor parte de ellas, suponían más de la mitad total de sus recursos (García García, 1996, pp. 55-56).

5 Respuesta del virrey a la consulta del cabildo de Guanajuato, México, 27 de febrero de 1783. AGN, Ayuntamientos, 134, exp. 5.

6 Copia certificada de la concesión y origen de los propios y arbitrios de esta ciudad, Guanajuato, 10 de noviembre de 1793. Archivo Histórico de la Universidad de Guanajuato (AHUG en adelante), Hacienda, Personal, 1787-1799, Caja 21. 


\section{PROPIOS Y ARBITRIOS DE GUANAJUATO (1788-1792)}

Antes de comenzar este apartado debe recordarse que, normalmente, la historiografía y las mismas fuentes históricas han separado los propios de los arbitrios. No obstante, también debe indicarse que tal división no ha sido aún sujeta a unos criterios específicos que los definan con claridad. Así, los distintos autores los han ido distinguiendo según sus criterios metodológicos concretos y en función de la información que tenían a disposición. Sirva de ejemplo González Beltrán, que para empezar establece la existencia de una multiplicidad de "haciendas municipales" surgidas de la conjunción en el marco legal de leyes generales de la Corona y las normativas locales. Entonces, para definir propios y arbitrios acude a Las Partidas, a la Novísima Recopilación y a los Autos Acordados, así como a las ordenanzas de cada ayuntamiento, sin olvidar tratados de autores de la época conocedores del régimen municipal, como Castillo de Bobadilla, Lorenzo Santayana Bustillo y Ramón Lázaro de Dou y de Bassols (González Beltrán, 1999, pp. 192-194). No obstante, también es cierto que en muchas cuentas de distintos cabildos indianos no se hacía tal división y, cuando se hacía, en algunos de ellos unas partidas se consideraban de propios o arbitrios mientras que, en otros ayuntamientos, los mismos conceptos eran asentados a la inversa.

En cualquier caso, también es cierto que algunas de esas rentas municipales sí suelen aparecer habitualmente como parte del mismo apartado. Por ejemplo, es frecuente que se señalen como arbitrios lo recaudado a partir de distintos impuestos, como la sisa o la alcabala, que grababan productos autorizados para su venta entre la población. También los cobros a productos y personas por el derecho a entrar a la localidad o a transitar por puentes y calzadas del municipio. Así, en el virreinato novohispano fue frecuente que los cabildos obtuvieran el derecho de recaudación de las alcabalas y de la sisa, como ocurría en el de Guanajuato. Por su parte, solían señalarse como propios las rentas resultantes del alquiler y provecho de ranchos, haciendas, ejidos, ubicaciones en mercadillos y plazas, tiendas o casas propiedad del ayuntamiento. Por tanto, de momento y mientras no se avance en una definición exacta, queda a criterio de cada historiador ordenar todos esos tipos de partidas, en función de un método historiográfico elegido, o de ceñirse al modo en el que la propia fuente lo describe y lo caracteriza. La elección no resulta baladí, toda vez que, en ocasiones, puede llegar distorsionar el enfoque según el método utilizado por unas instituciones u otras (Celaya Nández, 2017, pp. 375-397) o, incluso, a condicionar las conclusiones por una clasificación errónea o interesada. Y es que, en cada localidad solía estar especificada la finalidad de los ingresos según éstos fueran considerados propios o arbitrios (Pozas Poveda, 2011, pp. 83-256 y Blázquez Garbajosa, 1983, pp. 147-157).

En nuestro estudio seguimos el método de exposición utilizado por autores como Ensinck para el caso de Buenos Aires, un modelo sistemático y ordenado en función de la misma presentación que ofrecen los documentos originales consultados, pues 
resulta más funcional y ajustado a la realidad de cada municipio que el intento de crear métodos o clasificaciones metodológicas de carácter general que difícilmente se ajustan a esas numerosas particularidades (Ensinck, 1990). Por tanto, mostraremos las distintas partidas de los propios y arbitrios de la ciudad de Guanajuato, del quinquenio de 1788 a 1792, tal y como se presentaron en el informe elaborado en 1793 para dar respuesta a una orden de la Contaduría General de Propios y Arbitrios del Reino. Lo hacemos así porque resulta más convincente que, precisamente, esa ordenación responda a la manera en la que el mismo ayuntamiento, en aquel entonces, entendía cada uno de los ingresos municipales. Es decir, una presentación ajustada a la realidad del momento y de su tratamiento contemporáneo. Aparte, cabe decir que la importancia de este documento no se restringe únicamente al conocimiento exacto que aporta de las cuentas del municipio durante aquel quinquenio, sino que también es resultado de un esfuerzo por presentar el origen de algunos de aquellos ingresos y gastos, lo que permite un análisis más profundo de la realidad de la economía municipal guanajuatense en el conjunto del siglo XVIII. ${ }^{7}$ En cualquier caso, nos parece, la presentación exhaustiva de las cuentas correspondientes a las rentas municipales de, al menos, un quinquenio, resulta un ejercicio de ejemplificación muy útil que, a su vez, ayuda a sustentar gran parte de las afirmaciones vertidas en este y en otros trabajos anteriores ya mencionados más arriba.

Siguiendo la línea trazada al inicio de este trabajo, uno de los principales condicionantes para poder estudiar las rentas de una localidad es su propia geografía, la extensión de su jurisdicción y qué territorios exactos abarcaba. También el informe lo tuvo en cuenta, recordando que correspondían a la ciudad desde la obtención de aquel primer título de villa, 1.000 varas de longitud y otras tantas de latitud, lo que en realidad no se consiguió de pleno derecho hasta el pago de 200 pesos en la composición de tierras llevada a cabo en 1712. No nosotros, sino el mismo cabildo de Guanajuato, llamó a este derecho jurisdiccional "primordial dote de sus propios", pues esas mismas tierras y solares integrados en su interior podían ser objeto de venta a particulares por parte del municipio. Así, no extraña que el concejo, dominado ya a fines del siglo ilustrado por el poderoso grupo de mercaderes locales, se quejara amargamente de los privilegios del gremio minero. No en vano, aseveraban que había sido por la aplicación de esos privilegios por lo que en el pasado muchos mineros se habían apropiado indiscriminadamente de una parte importante de las tierras de la jurisdicción, para explotar el subsuelo. Lugares perdidos ya como propiedad de la comunidad y que no hacían más que seguir expandiendo sus lindes, como parte de la potestad para asentar cuadrillas en los alrededores de las minas para su habitación y acomodo. Toda una multitud de chozas y de ingenios mineros que el ayuntamiento consideraba irregulares, que mantuvo denunciados en la Audiencia durante décadas.

7 Copia certificada de la concesión y origen de los propios y arbitrios de esta ciudad, Guanajuato, 10 de noviembre de 1793. AHUG, Hacienda, Personal, 1787-1799, Caja 21. 
Unas denuncias que no dieron una solución y dejaron al ayuntamiento sin esperanza alguna de poder utilizar o vender sus terrenos en beneficio del común.

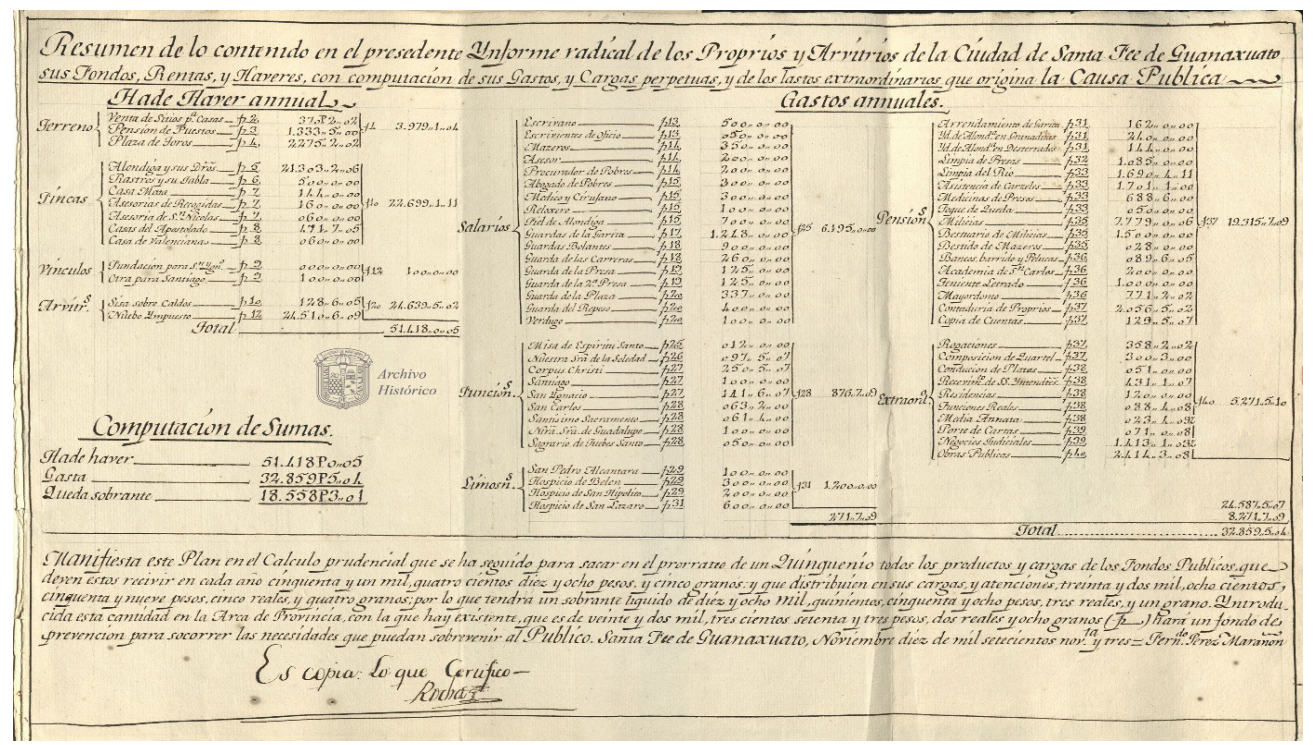

Resumen de la concesión y origen de los propios y arbitrios de Guanajuato, 10 de noviembre de 1793. AHUG, Hacienda, Personal, 1787-1799, Caja 21

En segundo lugar, señalaremos que el informe de 1793 sobre las cuentas se organizó, esencialmente y como solía ser habitual, en dos grandes bloques. Uno de ingresos anuales y el otro de gastos. Cada uno de ellos, a su vez, se ordenaron en ramos. El de ingresos se subdividió en cuatro apartados, denominados Terrenos, Fincas, Vínculos y Arbitrios, en cada uno de los cuales se señalaban los conceptos individualizados por los que se obtenían las rentas. Del mismo modo, los gastos quedaron relacionados en cinco partidas, intituladas Salarios, Funciones, Limosnas, Pensiones y Extraordinarios. Las distintas cantidades, tanto de ingresos como de gastos, aparecen de manera resumida en las tablas 1 y 2, evitando así una presentación confusa en modo de redacción. A la par, los facilitamos prorrateados por año, tal y como se hizo también en el propio informe, evitando una profusión innecesaria de datos sobre cantidades insustanciales que poco aportan al objeto final de este estudio, aparte de que tampoco cambiarían sus conclusiones.

De cada uno de todos esos ramos de ingresos y gastos se redactó un breve informe, en el que se intentó señalar no sólo el montante que suponía cada uno, sino también, en la medida de lo posible, su origen y una explicación de las problemáticas que afrontaban de forma particularizada. En algunos casos, como añadidura, se 
Economía municipal en el Guanajuato de las reformas borbónicas... - J.L. Caño

propusieron posibles soluciones para terminar con esos problemas e, incluso, maneras de optimizarlos.

\section{Ingresos}

Así, por ejemplo, en la descripción de lo cobrado por la explotación de los puestos de la plaza, ya se especificó en el informe que no se conocía a ciencia cierta el origen de este ramo. Lo único que podían asegurar sobre él, a partir de la documentación consistorial conservada en ese momento, era lo que aparecía por primera vez en sus escrituras correspondientes al año 1761. El expediente que conservaban se inició aquel año, cuando se constató que el procurador general no estaba cobrando los derechos que debía a los distintos regatones y mayoristas que introducían sus mercancías para distribuirlas entre los tenderos. Interesa saber que, al preguntarse sobre la reglamentación que se aplicaba, lo único que se informó fue que se hacía según la costumbre y del mismo modo que en otras ciudades del virreinato que sí contaban con reglamentación específica. Un testimonio muy general, sin indicar a qué ciudades o villas se estaban refiriendo. Lo único que sí se aclaraba es, por un lado, que existía un baremo para el cobro, según la ubicación del puesto en la plaza, oscilando desde los 2 reales de los más caros hasta el medio real de los más baratos. Y, por otro lado, que desde 1770 , dicha renta se estaba sacando a subasta anualmente para que la recaudara y administrara el mejor postor.

De la misma manera se hacía con la organización de las corridas de toros, que se celebraban los tres primeros días de noviembre, y el día de la patrona. En este caso, el ganador de la puja no sólo entregaba la cantidad señalada, sino que también debía hacerse cargo del montaje de la plaza, el tablado para el cabildo, la colocación de lumbreras, de la compra de los toros y caballos y, por supuesto, del salario de los toreros. Un festejo que, a la vista de esos gastos, podría resultar arriesgado. Pero lo cierto es que debía dejar pingües beneficios, única razón por la que puede parecer viable que se pagara al cabildo más de 11.000 pesos por las dos únicas corridas que se celebraron en todo el quinquenio estudiado.

En cuanto a las fincas, queda en evidencia que el cabildo de Guanajuato, siempre que lo creyó necesario, no dudó en especular dentro del mercado inmobiliario, como arrendador y arrendatario, comprando, vendiendo y alquilando diferentes inmuebles a lo largo de la centuria. Con ello fue utilizando distintas casas, edificios, locales y bodegas a su conveniencia, normalmente para destinarlas a pósitos, alhóndigas y carnicerías en propiedad o viviendas, mesones y tiendas en alquiler. Precisamente, el derecho de alhondigaje suponía, con diferencia, una de las dos mayores partidas de ingresos para el consistorio, por lo que extraña que, corroborando que se cobraba este derecho al menos desde el siglo XVII, de un real por cada carga de maíz y 2 reales por las de harina, se especificaba en el informe que no existió ninguna alhóndiga en la población hasta 1735. Más extraño resulta aun cuando, tras el 
pleito mantenido por el ayuntamiento con un religioso que se negaba a pagar los derechos de alhondigaje por su condición de eclesiástico, en la sentencia de la causa de 1716 se sustanció que las únicas bodegas que podían alquilarse para acumular grano debían ser las municipales. En cualquier caso, a pesar de que en el transcurso del siglo se construyeron varias alhóndigas, una de ellas quizá la más capaz de las Indias (Vargas, 2003 y Almanza Carranza, 2010), y se continuaron alquilando otros edificios por toda la población con el mismo fin, en 1761 se reguló que se podía pagar los derechos sin necesidad de depositar las cargas en ellas y venderlas directamente en las haciendas y minas repartidas por la jurisdicción. Un extremo que no impidió que siguieran siendo utilizadas y que en 1771 el virrey diera licencia para construir en la jurisdicción todas aquellas que fueran necesarias.

TABLA 1. ${ }^{1}$ Ingresos de las rentas municipales de Guanajuato (1788-1792). Prorrateados por año

\begin{tabular}{|c|c|c|}
\hline INGRESOS & CONCEPTO & $\begin{array}{c}\text { CANTIDAD } \\
\text { (redondeada, en pesos) }\end{array}$ \\
\hline \multirow[t]{4}{*}{ Terrenos } & Venta de solares para viviendas & 370 \\
\hline & Pensión de los puestos & 1.334 \\
\hline & Plaza de toros & 2.275 \\
\hline & TOTAL PARCIAL & 3.979 \\
\hline \multirow[t]{8}{*}{ Fincas } & Alhóndiga y sus derechos & 21.303 \\
\hline & Rastros y su tabla & 500 \\
\hline & Casa de Mata & 144 \\
\hline & Asesorías de Recogidas & 160 \\
\hline & Asesorías de San Nicolás & 60 \\
\hline & Casas del Apostolado & 472 \\
\hline & Casa de Valenciana & 60 \\
\hline & TOTAL PARCIAL & 22.699 \\
\hline \multirow[t]{3}{*}{ Vínculos } & Fundación de San Ignacio & 0 \\
\hline & Fundación para Santiago & 100 \\
\hline & TOTAL PARCIAL & 100 \\
\hline \multirow[t]{3}{*}{ Arbitrios } & Sisa & 129 \\
\hline & Nuevo Impuesto & 24.510 \\
\hline & TOTAL PARCIAL & 24.639 \\
\hline TOTAL & & 51.418 \\
\hline
\end{tabular}

Fuente: AHUG, Hacienda, Personal, 1787-1799, Caja 21.

1 En las Tablas 1 y 2 todas las cifras se expresan en pesos, con el objetivo de unificarlas y hacer más sencilla la contabilidad. Se han redondeado las cantidades, evitando expresar los reales, granos y tomines, facilitando la interpretación y tampoco suponer esta decisión una varianza significativa en el valor de cada partida contable ni en las conclusiones del estudio. 
Economía municipal en el Guanajuato de las reformas borbónicas... - J.L. Caño

Y lo eran, existiendo un buen número de ellas para atender las necesidades de la jurisdicción, de hábitat disperso debido a las distintas ubicaciones de los poblados mineros. Así, a fines del siglo XVIII eran diez las alhóndigas y alhondiguillas de Guanajuato. Entre todas, durante los años 1788 a 1792, suponían un trasiego de casi 630.000 cargas de maíz y más de 112.000 cargas de harina, lo que elevaba el valor del depósito en sus bodegas a casi 110.000 pesos, lo que generaba un beneficio de más de 21.000 pesos al año. Gracias a que, en la mayor parte de los casos, el salario de los fieles de estas alhóndigas iba en porcentaje de lo ingresado para incentivar su interés y vigilancia, con distintas modalidades de mejoras fijas del sueldo para compensar las alhóndigas que no manejaban grandes volúmenes, sabemos cuáles eran los barrios y poblados mineros que en aquellos años consumían más grano. Entendemos que ese mayor consumo revela que se trataba de barrios más ricos o populosos, por lo que contribuirían más al erario municipal. De esta forma, sabemos que la única alhóndiga que podía permitirse pagar un salario fijo a su fiel era la de Santa Ana, con 0. pesos al año. No obstante, la alhóndiga que más pagó a su fiel, en porcentaje, fue la de Santa Rosa, con $00 \wedge$ pesos de media al año. Parejas eran las ricas alhóndigas de los barrios de Granaditas, Desterrados y del Real de Marfil, donde rondaban los 470 pesos al año de sueldo a sus fieles. Unas cifras a donde no llegaba ya, un poco más distante en volumen de depósito, la de Valenciana, que pagaba poco más de 300 pesos a su responsable. Más lejos y pobres quedaban después, por este orden, las de Sirena, Cata, Mellado y San Bruno, entre 190 pesos de máximo y 62 de mínimo.

Por su parte, la entrada principal de la ciudad, por la cañada del real de Marfil, se configuró como un lugar esencial para todo lo concerniente al cobro de derechos municipales, pues allí se situó el rastro de venta de carne al por mayor, el depósito de pólvora y la garita principal de inspección de entrada de productos a la ciudad. En cuanto al rastro se debe decir que se reubicó en un lugar más grande y mejor acondicionado en 1774, a la entrada de la ciudad. En este caso, para las fechas del informe también se había perdido toda documentación anterior que hiciera referencia al mismo, pero al menos sí sabemos que en aquellos momentos la forma de explotarlo era arrendando sus derechos por 500 pesos anuales, un dinero con el que, entre otras cosas, se aprovechó para costear la construcción de unas oficinas para su administración y para la expedición de carnes. También en 1774 se decidió el traslado a este paraje del almacén de pólvoras, llamado Casa Mata en Guanajuato, exactamente junto al Real Estanco. Dicho traslado era lógico, pues su ubicación en el centro de la ciudad suponía un enorme peligro de explosión e incendio, aunque se dejó en uso el antiguo para la venta de pequeñas cantidades. Por ambos inmuebles, y por orden del virrey, el administrador de este ramo debía pagar en concepto de alquiler 144 pesos al año, haciéndolo efectivo a razón de 12 pesos cada mes.

Una cantidad parecida, 160 pesos al año, se conseguían con el arrendamiento por partes de la Casa de Recogidas, un edificio cuyos locales y bajos se cedían a bajo precio para su uso como viviendas a familias pobres y necesitadas de la ciudad. 
En este caso recomendaba el alférez real que se abandonara dicho uso y que, por su mayor tamaño y mejores condiciones, se dedicara a cárcel, toda vez que la existente presentaba demasiados y urgentes problemas. Tampoco era éste el único inmueble que disfrutaba la ciudad y que dedicaba al alquiler como viviendas para obtener beneficios. Con el tiempo, el ayuntamiento supo sacar partido de la construcción de algunos puentes que se hicieron necesarios, utilizando las estructuras y aledaños de éstos para añadir casas que arrendar, a la par que aportaban el doble beneficio de actuar como elementos de disuasión sobre el habitual refugio y vía de escape que los delincuentes solían hacer de los bajos de aquellos puentes. Algunas de esas casas fueron la del puente de San Nicolás, que dejaba una ganancia de 60 pesos al año y la construcción de doce "casitas" en el puente de San Ignacio, que rendían una media de algo más de 470 pesos anuales sacándolas a subasta cada año. En este último caso, además, se hicieron para urbanizar e higienizar la zona, creando una nueva calle justo enfrente de la casa de ensaye de platas. Por último, otro inmueble al que le sacaba provecho el consistorio era la casa de la alhóndiga del poblado minero de $\mathrm{La}$ Valenciana, que compró en 1789 por 550 pesos para no tener que pagar el alquiler, lo que hacía ahorrar al ayuntamiento 60 pesos por año.

Un tercer ramo de ingresos lo constituían lo que el cabildo daba en llamar utensilios o auxilios, que eran los vínculos donados en favor de las rentas municipales por algunos particulares para ser administrados y dedicados para una actividad específica cada año. Fue lo acaecido con dos fundaciones entregadas para honrar a los santos Santiago y San Ignacio en sus respectivas festividades. La primera suponía 100 pesos de ingreso -y de gasto directo en su día- derivados de los 2.000 pesos de la hipoteca de unas casas en la plaza mayor, donados la mitad por Ana Gil de Taboada antes de su fallecimiento, y la otra mitad por voluntad de su propio albacea sobre la misma herencia. Mientras, el segundo vínculo fue instaurado en 1725 y 1729 por el prominente vecino Pedro Aguirre Acharán, con un capital total de 1.000 pesos sobre casas hipotecadas de unos préstamos que concedió y que reportaban 50 pesos anualmente. Pero esta donación quedó en nada poco tiempo después de la expulsión de los jesuitas.

Distintos a todos los anteriores eran los arbitrios, que se solían obtenerse en forma de impuestos por algún concepto, bien de forma temporal o permanente, según fuera la licencia concedida y el destino dado a lo recaudado. En Guanajuato llamaron arbitrios a dos impuestos, por un lado, la sisa, que allí grababa la venta de vinos, aguardiente y tabaco desde 1760. Y por otro, el nuevo impuesto, implantado en 1767 como una imposición extraordinaria para hacer frente a los gastos ocasionados por las distintas revueltas de "plebeyos y operarios de minas". En realidad, el primero de estos dos impuestos también se originó por los enormes costes imprevistos que había que asumir para evitar futuros desastres por inundaciones como los producidos en 1760. En efecto, de inmediato se comenzaron no sólo obras de reparación y desescombre de todo lo dañado, sino también la construcción de nuevos puentes, pretiles, la caja del río y la derivación de casas y otros edificios. Unas obras que, en principio, se presupuestaron en 150.000 pesos de plata, pero que, a la postre, 
Economía municipal en el Guanajuato de las reformas borbónicas... - J.L. Caño

superarían esa cifra con holgura. El sobrecoste pudo permitirse por el alargamiento indefinido del cobro de este impuesto, licenciado por el virrey aquel mismo año de la inundación, pero sólo hasta que se acabaran las obras necesarias. La licencia permitía gravar el vino y aguardiente de Castilla con cuatro pesos por barril, los de la tierra o parras con un peso, que serían dos si se presentaba en botellas y, finalmente, tres pesos por barril de tabaco. En realidad, las nuevas obras nunca acabaron del todo, pues siempre se necesitaron más debido al crecimiento de la ciudad y a su complejidad urbanística. No obstante, la sisa sí llegó a su fin con el definitivo estanco estatal del negocio del tabaco y con la prohibición borbónica de cobrar imposiciones a los vinos de Castilla.

Por lo que respecta al nuevo impuesto, se licitó tras los disturbios de 1767 y la reunión que el visitador Gálvez tuvo con la "Junta de vecinos", compuesta por el cabildo y las diputaciones de comercio y de minería. En esta reunión coincidieron en la necesidad de recaudar más dinero, con objeto de, por un lado, de construir más puentes y una nueva calzada de entrada a la ciudad que evitara la peligrosa cañada que se utilizaba habitualmente. Y, por otro, poder realizar una limpieza anual del río y crear una compañía permanente de milicianos en la ciudad, compuesta por un total de 46 hombres y sus caballos que cobrarían tres reales por día, lo que suponía un total de 50.370 pesos al año. Una sustanciosa cantidad que sólo podría obtenerse gravando algún bien de consumo habitual. En efecto, se decidió imponer un real a cada fanega de maíz y dos reales a cada carga de harina que se vendieran en la ciudad. Ello podría parecer un añadido a lo que ya se cobraba por derechos de alhondigaje, pero había tres diferencias fundamentales. Primero, que el nuevo impuesto lo costeaban comprador y vendedor, no sólo el introductor de la mercancía; segundo, que el maíz se cobraba por fanega y no por carga, siendo cada carga de unas dos fanegas y media; y, tercero, que se trataba de un impuesto temporal y no permanente. Por último, cabría preguntarse si con este tipo de cobros consiguieron llegar a la cifra que pretendían, a lo que habría que responder que se quedaron lejos de la intención inicial. De hecho, se quería recaudar más de 50.000 pesos al año, y la media anual conseguida entre 1788 y 1792 fue de 24.510 pesos, correspondiendo poco más de 18.000 al maíz y el resto a las harinas. Estas cantidades declaradas confirman que en Guanajuato se consumieron en cinco años casi 750.000 fanegas de maíz y más de 116.000 cargas de harina. Un extremo que, por sí solo, evidencia el tamaño y la importancia de la ciudad, más aún si ponemos en valor el matiz indicado anteriormente de que son valores sobre mercancías declaradas, sin poder conocerse a ciencia cierta el volumen de lo introducido ilegalmente.

En definitiva, esta recaudación en concepto de arbitrios, sisa y "nuevo impuesto", constituían los ingresos de mayor cuantía del ayuntamiento guanajuatense a finales del siglo XVIII, representando, entre 1788 y 1792, 24.510 de los 51.418 pesos que se recaudaron en total. Unos ingresos que, junto con los del alhondigaje, sustentaban el potencial económico del municipio. Ahora bien, poca capacidad de previsión podían 
tener para planear gastos futuros, toda vez que se trataba de impuestos licitados como mercedes extraordinarias y temporales.

\section{Gastos}

Una vez conocidos los ingresos, puede afirmarse que, en comparación, eran muy superiores a los de otras muchas ciudades de la América española. Entre esas ciudades se encontraban, incluso, capitales virreinales como Buenos Aires, que no llegarían a cantidades similares hasta bastantes años después (Ensinck, 1990). Es entonces cuando pueden entenderse mucho mejor las posibilidades de las que disfrutaba Guanajuato para afrontar su desarrollo municipal, tanto en lo político, lo económico, lo social, lo militar y lo urbanístico, siendo esto último lo que ha dejado más rastro hasta hoy (Díaz Berrio, 1972, pp. 221-233). ${ }^{8}$

De hecho, aun cuando era imposible conocer con exactitud los ingresos que generarían a lo largo del año, el cabildo guanajuatense sí podía anticipar algunos gastos que, por su necesidad ordinaria, comenzaron a considerarse como gastos fijos anuales. A este tipo de gastos, en el siglo XVIII, los responsables de las cuentas municipales los llamaban pensiones y salarios. Estas dos partidas, como puede verse en la Tabla 2, junto con los imprevisibles egresos extraordinarios, representaban el grueso de los gastos capitulares. Como era lógico, la corporación fue aumentando sus estipendios al ritmo que la misma ciudad fue creciendo a lo largo del siglo XVIII, entre otras cosas por la misma evolución que experimentó en importancia política y social, al calor del aumento de su riqueza minera (Hernández Chico, 1976, pp. 15-31. Galindo Montiel, 1992. Serrano Espinoza y Cornejo Muñoz, 1998) y de su desarrollo y diversificación económica.

El mismo cabildo se fue convirtiendo poco a poco en una institución cada vez más vasta y compleja, en función de nuevas necesidades que iban apareciendo. Ello redundó en la contratación de funcionarios y profesionales que les dieran una respuesta adecuada, que aumentaron en número y en diversidad de responsabilidades. Así, a fines del siglo XVIII, el consistorio era una institución mucho más variada que la de una sencilla reunión de regidores y alcaldes mayores con algunos pocos auxiliares. Ahora, se sumaban también un buen número de distintos empleados que abarcaban un extenso abanico de funciones públicas. De forma sucinta pueden verse todos en la Tabla 2, al menos los que cobraban directamente un salario del ayuntamiento, lo que no evita la oportunidad de aportar algunas explicaciones sobre algunos de ellos.

8 Destacamos también el importante conjunto de Tesis que, sin publicar, pero entre sus fondos consultables, se han defendido en la Universidad de Guanajuato acerca de la evolución de su urbanismo colonial, y en especial en el siglo XVIII, tanto en la División de Ciencias Sociales y Humanidades como en la Facultad de Arquitectura. 
Economía municipal en el Guanajuato de las reformas borbónicas... - J.L. Caño

TABLA 2. Gastos de las rentas municipales de Guanajuato (1788-1792)

Prorrateados por año

\begin{tabular}{|c|c|c|}
\hline GASTOS & CONCEPTO & $\begin{array}{l}\text { CANTIDAD (redondeada, } \\
\text { en pesos) }\end{array}$ \\
\hline \multirow[t]{10}{*}{ Salarios } & Escribano de cabildo y escribientes & 550 \\
\hline & Maceros & 350 \\
\hline & Asesor & 200 \\
\hline & Procurador de Pobres & 200 \\
\hline & Abogado de pobres & 300 \\
\hline & Médico y cirujano & 300 \\
\hline & Relojero & 100 \\
\hline & Fiel de Alhóndiga & 700 \\
\hline & Guardas (garitas, presas, plazas y repesos) & 3.395 \\
\hline & Verdugo & 100 \\
\hline & TOTAL PARCIAL & 6.195 \\
\hline \multirow[t]{9}{*}{ Funciones } & Misa Espíritu Santo & 12 \\
\hline & Nuestra Señora de la Soledad & 98 \\
\hline & Corpus Christi & 250 \\
\hline & Santiago & 100 \\
\hline & San Ignacio & 142 \\
\hline & San Carlos & 63 \\
\hline & Sacramento & 61 \\
\hline & Nuestra Señora de Guadalupe & 100 \\
\hline & Sagrario de Viernes Santo & 50 \\
\hline & TOTAL PARCIAL & 877 \\
\hline \multirow[t]{4}{*}{ Limosnas } & Convento San Pedro de Alcántara & 100 \\
\hline & Hospicio de Belén & 300 \\
\hline & Hospicio de San Hipólito & 200 \\
\hline & Hospicio de San Lázaro & 600 \\
\hline & TOTAL PARCIAL & 1.200 \\
\hline \multirow[t]{13}{*}{ Pensiones } & Arrendamientos de garitas y alhóndigas & 546 \\
\hline & Limpieza anual de presas y río & 2.775 \\
\hline & Asistencia de cárcel y medicinas para reos & 2.390 \\
\hline & Campanadas y toque de queda diario & 50 \\
\hline & Salarios de milicias y uniformes & 9.279 \\
\hline & Vestido de maceros & 28 \\
\hline & Adecentado de bancos, barrido y pelucas & 90 \\
\hline & Academia de San Carlos de México & 200 \\
\hline & Teniente letrado & 1.000 \\
\hline & Mayordomo & 771 \\
\hline & Hacienda y Contaduría Mayor de Propios & 2.057 \\
\hline & Copia de las cuentas para la Intendencia & 130 \\
\hline & TOTAL PARCIAL & 19.315 \\
\hline
\end{tabular}


Revista de Humanidades, 43 (2021). p. 19-47. ISSN 1130-5029

\begin{tabular}{|l|l|r|}
\hline Extraordinarios & Rogaciones & 358 \\
\cline { 2 - 3 } & Composición del cuartel de milicias & 300 \\
\cline { 2 - 3 } & Conducción de platas & 51 \\
\cline { 2 - 3 } & Recibimiento de autoridades & 431 \\
\cline { 2 - 3 } & Juicios de Residencia & 120 \\
\cline { 2 - 3 } & Funciones Reales & 89 \\
\cline { 2 - 3 } & Media annata & 23 \\
\cline { 2 - 3 } & Correos & 71 \\
\cline { 2 - 3 } & Negocios judiciales & 1.413 \\
\cline { 2 - 3 } & Obras públicas & 2.415 \\
\hline & & $\mathbf{5 . 2 7 2}$ \\
\hline TOTAL & $\mathbf{3 2 . 8 5 9}$ \\
\hline
\end{tabular}

Fuente: AHUG, Hacienda, Personal, 1787-1799, Caja 21.

Y es que, en efecto, gracias al informe no sólo podemos saber qué oficios se desempeñaban en el consistorio, sino que, unido a algunas de nuestras investigaciones anteriores ya citadas, también es posible conocer su existencia anterior y su evolución antes de que la urbe fuera elevada con el título de ciudad en 1741 y su ayuntamiento conformado como a esa calidad correspondía. Ese es el caso, por ejemplo, del escribano de cabildo, un oficio que aparece ya a fines del siglo XVII con la obtención del título de villa. Pero, este codiciado puesto no siempre representó el mismo coste para la población, experimentando su salario una evolución desde los 200 pesos anuales que cobraba a principios de la centuria hasta los 500 que le fueron aprobados como sueldo en 1770 y confirmado en 1773 en el reglamento de subdelegados. Un estipendio que, incluso reconocido por el mismo ayuntamiento, resultaba escaso sólo quince años más tarde, debido a la enorme carga de trabajo que soportaba y la necesidad de sostener a más escribientes a su servicio. Escribientes que, en algunos casos, pagaba el propio notario del cabildo directamente, pero de cuyo mantenimiento, en otros casos, se hacían cargo las rentas de propios. Una circunstancia que se extendía a los amanuenses del escribano de presos de la ciudad.

También consideraban las autoridades de la ciudad que los dos maceros estaban mal pagados, unos puestos que fueron creados para dar lustre a las ceremonias del cabildo. Un brillo que difícilmente se podía conseguir, decía el alférez real en su informe, con el escaso salario que recibían, que no les daba ni para pagarse unas ropas decentes con las que vestir cotidianamente. Y ello aun cuando se les había subido algo la paga, sumándoles la responsabilidad de porteros del cabildo. En este sentido, recordaba el regidor decano, los maceros no sólo representaban el esplendor de la institución en las ceremonias, sino también en el diario, en cualquier momento y lugar de la ciudad. Interesa especialmente la información que se aporta en este apartado 
del informe, ya que para su argumentación el regidor señalaba, explícitamente, que Guanajuato era una de las ciudades más caras de todo el imperio, razón por la que lo sueldos debían de ser más elevados si se pretendía que los empleados municipales pudieran llevar una vida decente y acorde al fulgor de la institución para la que trabajaban y a la que representaban. Se pidió entonces un aumento del salario de los maceros, para evitar que los únicos candidatos a ocupar esos puestos fueran, como venía ocurriendo, "enfermos y viejos que poco sirven a la ciudad y ridiculizan su oficio".

A la par que aumentaba el lustre del consistorio, también lo fue haciendo el de oficios que permitían una mejor administración y gestión. De este modo, en 1775 se añadió el puesto de asesor letrado, aunque con un escaso sueldo de 200 pesos que sólo permitía, todavía en la última década del siglo, que lo ocupara el cabildante que abogó por su creación. Mismo salario que recibía también el procurador de pobres y de reos, a pesar de que este puesto se creó a petición del cabildo y con licencia para darle un sueldo competente. ${ }^{9}$ Una gratificación que, a su vez, era poco menos de lo que percibía el abogado de pobres, 300 pesos, y suponía el doble de lo que cobraban el médico y el cirujano municipales. Unos profesionales estos últimos que, realmente, sólo cobraban 50 pesos más al año que el relojero, un oficio del que se desconoce desde cuando existía en la ciudad, pero al que se le responsabilizó del nuevo reloj que, para la torre parroquial, se compró en Londres y cuyo manejo del mecanismo fue necesario que aprendiera. Si estaban mucho mejor pagados los fieles de las distintas alhóndigas que se fueron construyendo en la ciudad, al menos de las más importantes, pero no nos detendremos aquí por haber sido ya explicado más arriba este extremo. Sólo añadiremos ahora que con sus salarios debían pagar a los escribientes que necesitaban, quienes asentaban las partidas de granos y harinas en los libros que cada pósito debía llevar individualizado y se encargaban de elaborar las boletas que debían identificar a cada carga que entraba y salía de la ciudad.

Unas mercancías cuya entrada y salida debían vigilarse bien, para evitar fraudes y contrabando. Esto se conseguía con un numeroso y preciso cuerpo de guardas, que se situaban en garitas ubicadas en las distintas entradas a la localidad. Comenzaron a colocarse a partir de la consecución del título de ciudad, siendo la más importante de ellas la que controlaba el paso proveniente del camino real que ingresaba a Guanajuato por la cañada de Marfil. Cobraba este guarda 800 pesos al año, pero debido a la cantidad de tráfico de mercancías que soportaba este camino en 1774 se vio la necesidad de poner dos guardas que pudieran evitar las aglomeraciones y los pasos incontrolados que se derivaban de esa situación. Para poder afrontar el coste de esa doble inspección, se les asignó a ambos guardas un salario de 600 pesos anuales, una cantidad bastante menor de la que percibía el guarda volante, encargado de evitar el contrabando de regatones y revendedores que se producía por las distintas

9 Poder del cabildo para solicitar el puesto de procurador de pobres y reos, Guanajuato, 14 de octubre de 1730. AHUG, PCL, 1730, f. 401. 
veredas existentes en las montañas colindantes. Este guarda de montaña comenzó cobrando 520 pesos al año, pero, para poder garantizar su efectividad esta cantidad debió elevarse a 900 pesos. Sólo así podía hacer frente a los 400 pesos anuales que costaba un ayudante y tener una cuadrilla de hombres dispuesta. Pero lo cierto es que, tampoco así, pudo evitarse la existencia de un contrabando masivo. De hecho, el cabildo también sumó al anterior otro guarda específico en uno de los caminos más confluidos y donde más tráfico ilegal se producía, el del cerro de las Carreras.

Unos guardas a los que acompañaban los que custodiaban algunas instalaciones municipales especialmente sensibles, como las presas, en las que había que controlar la limpieza del muro y el buen uso del agua para evitar su contaminación, atendiendo a la idea "circulacionista" de moda en aquellos años (Reza, 2001, pp. 61-63). Se vigilaba en ellas, especialmente, que no se echaran desperdicios, animales muertos, vertidos de las minas y de las haciendas de minas, o que se lavara en ellas ropa y utensilios. Estos guardas de presas se instituyeron desde su construcción, es decir, desde 1746 para la presa de la Olla, y desde 1790 cuando se terminó la de Pozuelos. Estos empleados recibían bajos salarios, que no hacía más que obligarles a buscar otras actividades con las que poder mejorar su situación económica. Tanto es así que distraían bastante su labor de vigilancia, aun cuando vivían en las casas construidas específicamente para ellos junto a las presas. Finalmente, había dos guardas municipales más, uno que evitaba la actividad de vendedores ilegales en las plazas de mercado y otro que, desde 1789 , controlaba que las carnes vendidas en el rastro estuvieran en buen estado y no fueran objeto de precios abusivos. Al primero, para evitar situaciones como las anteriores de empleados mal pagados, se le concedió un buen salario de 337 pesos al año, pero haciéndole responsable también de la limpieza de los distintos almacenes del ayuntamiento, donde se guardaban los materiales de construcción, los utilizados en los festejos, etc. Al segundo, debido a su responsabilidad en la salubridad alimentaria y control de precios de venta de un bien básico, se le retribuía con 400 pesos anuales.

Por último, se mantenía otro empleado público esencial y permanente, como lo era el verdugo. Fue este un oficio al que se comenzó pagando únicamente cuando se le necesitaba, es decir, por ejecución llevada a cabo. Se desconoce la cantidad que cobraba antes de iniciarse la aplicación de las reformas ilustradas, pero sí se sabe que empezó a ser más rentable pagarle un salario fijo de 50 pesos anuales. Más tarde, los reglamentos de la segunda mitad del siglo XVIII fijarían la cantidad de dos pesos por ejecución, a lo que el ayuntamiento respondió decidiendo pagarle hasta 100 pesos al año para evitar que el gasto fuera mayor.

Todos los salarios expuestos suponían una, más o menos, una cantidad escasamente variable que el procurador general del cabildo conocía y podía tener en cuenta a la hora de planear el presupuesto consistorial anual. De la misma manera que, como indicábamos más arriba, conocía otros fuertes gastos fijos que cada año debían realizarse, a los que llamaban pensiones. Básicamente, se trataba del alquiler 
de algunos edificios indispensables para su utilización como pósitos o como garitas, de las costosas limpiezas anuales del río y de las presas, del mantenimiento de la cárcel, el sostén de las milicias y la entrega a la Contaduría Superior de Propios y Arbitrios, así como al Mayordomo, de sus respectivos porcentajes sobre la cantidad total de ingresos obtenidos. Todo ello entre otros gastos de menor calado. Algunos de estos gastos no necesitan de mayor explicación, por su sencilla sustancia, pero a otros les dedicaremos unas líneas. Y es que hay algunos que resultan de interés para un mayor conocimiento de la naturaleza de las cuentas municipales.

Es el caso de las limpiezas de las presas y del río, cuya variabilidad en el gasto anual era enorme según la situación que presentaban las balsas de ambas presas y el cauce del río, entre 5.000 y 14.000 pesos según cada año (Reza, 2001, pp. 64-138). ${ }^{10}$ Ello dependía tanto del atierre provocado por la distinta sedimentación anual, según hubiera llovido más o menos, así como por la cantidad de deshechos echados por los vecinos. También ayudaba a las labores de limpieza el hecho de que, mientras se hacían, lloviera y se crearan torrentes de arrastre, al modo en el que aún hoy se hace en el momento de desagüe de la presa de la Olla una vez al año. El caso es que eran muy habituales los arrojos de escombros y basuras, que solían cegar los ojos de los distintos puentes y taponar la caja del río. Esa situación, en épocas de lluvia, provocaba fuertes y frecuentes inundaciones, en las que se perdían muchas vidas y enseres. Perfectos conocedores los virreyes de esa realidad, incluyeron como uno de los objetivos del nuevo impuesto el pago de las limpiezas del río, que se tasaron y limitaron en 1787 a algo menos de 8.000 pesos anuales. Una escasa cantidad protestada por el cabildo que, a la espera de una resolución definitiva por parte del virrey, se decidió aplicar arriesgando la seguridad de los vecinos al no gastar más allá de lo estrictamente urgente. Es por ello que las cuentas del quinquenio de 1788 a 1792 arrojan una media anual en este concepto de tan sólo 1.690 pesos, lo que no daba para mucho más que la limpieza de los ojos de los puentes.

Una pequeña cantidad la anterior que se asemejó a la gastada, por ejemplo, en el mucho más modesto mantenimiento de la asistencia a la cárcel y a sus presos, una labor en la que, por cierto, también ayudaban los padres franciscanos con sus limosnas. Gastaba el consistorio unos 2.400 pesos anuales en este apartado, prácticamente casi todos dedicados a la comida de los reos y a la limpieza de las instalaciones, aunque casi 700 se iban a la compra de medicinas. Pago de la comida con la que se conseguía un doble objetivo, pues se le encargaba a la cocina de la Casa de Recogidas, institución que obtenía ese dinero también ayudando a su supervivencia.

10 El estudio de las obras de limpieza del río, encajonamiento de su cauce y la construcción de puentes en el Guanajuato de fines de la colonia merece un estudio aparte, véase para su documentación: AHUG, Actas de Cabildo, Tomos 1778-1782.- AHUG, Citadino, Puentes y Bóvedas, Caja 1, 17501783, Expedientes 1, 2, 3 y 4: Sobre la limpieza del río y construcción de puentes, 1750 y 1784-1796.AHUG, Citadino, Puentes y Bóvedas, Caja 2: Sobre obras públicas y limpia del río, en siglo XIX, $1820-1835$. 
Al contrario, sí suponía un fuerte esfuerzo económico el mantenimiento de las milicias locales permanentes. No sólo porque eran 46 milicianos salario, como se indicó con anterioridad, sino que también necesitaban de uniformes, armas y un cuartel con dependencias suficientes. Estas necesidades cuartelarias siempre fueron en aumento y debían dar respuesta al decoro que demandaba una institución militar de la Corona como la que representaban. Y si bien para la construcción, ampliación y mantenimiento del cuartel se sacaron partidas extraordinarias, que veremos más abajo, sólo el mantenimiento de los soldados suponía un poco menos de los 8.000 pesos autorizados por el virrey, lo que motivó la solicitud del Intendente en 1792 que pudiera elevarse el número de militares a 63 , contando con tres sargentos, ocho cabos y dos tambores, además de 50 soldados rasos. Debe tenerse en cuenta que ese mismo año de 1792 se probó a sustituir el piquete miliciano guanajuatense por una Compañía de Veteranos Voluntarios de Cataluña, pero en pocos meses se olvidó la idea de continuarla porque su gasto se elevó hasta casi los 14.000 pesos. Por otra parte, estaba el coste de las armas y uniformes, representando el primero la mitad que el segundo al prorratearlos anualmente. Y es que las armas, aunque más caras, duraban muchos años, al contrario que los uniformes, que se estropeaban. Así, de promedio, se gastaba en ropa unos 25 pesos por soldado y año, lo que suponían unos 1.500 pesos en total al subirse el número de milicianos a 60 . Mientras que en armas se gastaron poco menos de 8.000 pesos, de una vez en 1783, lo que arrojaba un promedio anual de unos 800 pesos al año.

De la misma manera que también representaba una importante cantidad para el concejo hacer frente a obligaciones reglamentadas a partir de las reformas borbónicas. Nos referimos, fundamentalmente, a las tres partidas impuestas para el sostén y buen funcionamiento de instituciones superiores, como la Contaduría Superior de Propios y Arbitrios, el Mayordomo de las cuentas y el Teniente Letrado asesor del Intendente. Correspondía a la primera el 4\% del total de lo ingresado anualmente por el ayuntamiento, lo que en el quinquenio estudiado supuso una media anual de más de 2.000 pesos. A la par, el consistorio debía hacerse cargo del salario de 1.000 pesos anuales del asesor del Intendente y, también, pagar el $1,5 \%$ del total de los ingresos a lo que tenía derecho el Mayordomo y revisor de las rentas municipales, que representó una cantidad media anual de algo más de 770 pesos. Consecuentemente, el ayuntamiento ayudaba a sostener el gobierno superior de sus propias rentas con casi 4.000 pesos al año, si añadimos los casi 130 pesos que costaba también pagar al escribiente de la Intendencia el coste de copiar los libros de cuentas para que los intendentes también los tuvieran a disposición y resguardo.

La otra gran partida del gasto municipal era la dedicada a los imprevistos, urgencias y otros extraordinarios que, como es lógico, surgían cada año. Sin duda, entre éstos destacaban los referentes a reparaciones y obras urgentes en infraestructuras de la ciudad, así como en el mantenimiento de los pleitos judiciales en los que debía embarcarse el municipio, bien como demandante o bien como demandado. De hecho, entre ambas partidas se gastaron una media anual de casi 
Economía municipal en el Guanajuato de las reformas borbónicas... - J.L. Caño

4.000 pesos de los poco más de 5.000 del total que supuso este asiento cada año entre 1788 y 1792.

No nos parece necesario detenerse en la explicación de las obras públicas, pero si lo haremos, aunque sea rápidamente, en los negocios judiciales como les llamaban los responsables de las cuentas. Y es que, efectivamente, el cabildo soportaba en aquellos años varios pleitos para defender el interés público, lo que obligaba a costear numerosas diligencias. Para ello, se contaba con un apoderado en la corte virreinal, un coste para el que la ciudad todavía nunca había conseguido autorización pero que, sabemos, pocas veces dejó de tener desde mediados del siglo XVII. Apoderados que, en muchas ocasiones, los cabildantes aprovechaban para situar a abogados guanajuatenses que residían en México. Aseveraba el regidor decano que ello era posible porque si bien no tenían la autorización, tampoco tenían ninguna orden dada en contra de ello. Era la razón por la que no se le podía asignar un salario fijo de los propios del ayuntamiento, pero sí se le sacaba como partida extraordinaria los 200 pesos al año que se le entregaban. Una cantidad que, en cualquier caso, resultaba irrisoria para lo que solían cobrar este tipo de agentes en la capital. Tanto es así que, se temía el alférez real que realizaba el informe en 1793, que pronto dejarían de tener agente en la capital si no se conseguía aumentar y fijar de manera estable ese salario. En este sentido, también apuntaba que no se asentaba en dicho informe las cantidades entregadas al apoderado de la ciudad en la corte de Madrid, para lo que sí tenían licencia desde 1778, aunque sin habérsele señalado cantidad fija y únicamente se le gratificaba en función de los trabajos que fuera haciendo.

En resumen, terminaban estos gastos extraordinarios con partidas como las dedicadas a los distintos novenarios que se pagaban para rogar por el fin de epidemias, malas cosechas, sequías, etc. También en ceremonias como las que se realizaban a la hora de recibir a autoridades, como los intendentes cuando llegaban a tomar posesión, o las dedicadas a celebrar los felices sucesos que acaecían a la familia real y que venían ordenadas en circulares cuando éstas se producían. Tampoco dejaban de pagarse los portes que suponían la llegada de esos correos y otras órdenes superiores, o el de la conducción de plata del rey o presos hasta la frontera con la siguiente jurisdicción en el camino a la capital, es decir, Celaya. Como también se pagaban los juicios de residencia de las autoridades salientes del cabildo, pagando 600 pesos a los jueces en cada ocasión, y sin olvidar la media annata correspondiente al título de ciudad obtenido en 1741, de 300 pesos cada quince años.

No puede terminarse, en cualquier caso, sin señalar otro tipo de estipendios que, si bien representaban una cantidad menor dentro de los presupuestos municipales, ameritan una explicación por no dejar de ser significativos sobre la evolución de los tiempos. Entre ellos podrían haber sido objeto de nuestro interés gastos anecdóticos, pero no despreciables, como lo era el peinado de las pelucas de los cabildantes, en lo que, junto a la limpieza de los bancos para las ceremonias, se gastaba una media de casi 90 pesos al año. Pero, en realidad, nos referimos sobre 
todo a la dedicación de casi 2.000 pesos anuales a celebraciones religiosas, ayuda a instituciones hospitalarias, educativas, obras pías y limosnas. En ese sentido, no deja de llamar la atención el hecho de que Guanajuato ayudaba al oneroso mantenimiento de algunas instituciones de otras localidades, concretamente en México, para la que se desviaban fondos municipales.

Sea como fuere, el primer gasto religioso que cada año hacía la ciudad se producía cada primero de enero con la misa del Espíritu Santo, a la que asistía el cabildo en pleno para, entre otras cosas, pedir por el acierto e inspiración divina en la elección de los cargos anuales del ayuntamiento, lo que suponían 12 pesos. Mucho más dispendiosa resultaba la celebración de la Soledad el Viernes Santo, que se hacía al modo de la capital virreinal con misa de Santo Entierro. Se trataba de un gasto que antiguamente asumía la diputación de comerciantes locales, gastando casi 100 pesos si se incluía la compra de la cera necesaria. Pero, desde que la gestión de las alcabalas pasó del arriendo de los comerciantes a administrarlas directamente el consistorio, fue éste el que se hizo cargo de esa ceremonia religiosa. De todas formas, la autoridad superior, por medio del reglamento impuesto por el Tribunal de Propios y Arbitrios, limitó las cantidades que debían gastarse en ésta y en otras liturgias, para dedicar el resto de dinero a otras obras de servicio social. No obstante, en algunos de esos casos los cabildantes se resistieron a recortar en este tipo de gastos, aduciendo que su ciudad era "el lugar más caro del reino" y que, además, los costes estaban sujetos también al antojo de los sacristanes. Hasta tal punto no se cumplía lo ordenado y podía resultar caro que, en la festividad religiosa más onerosa de la ciudad, el Corpus Christi, se gastaban hasta 250 pesos cada año. Es decir, 100 pesos más de lo autorizado por las autoridades superiores. Y es que, entre los gastos que se efectuaban en ese concepto, estaba el enramado y sombreado de la calles y plazas por donde debía pasar la procesión.

Al menos, otras ceremonias religiosas, como las de Santiago patrón de las Españas y San Ignacio, patrón de la localidad desde 1724, no debían representar tanta preocupación dineraria para el ayuntamiento, toda vez que la primera se costeaba con la donación de una renta de 100 pesos que, para ese fin, hizo a principios de siglo Ana Gil de Taboada. Por su parte, la segunda, se costeaba con otra donación parecida de Pedro Aguirre Acharán. No obstante, la renta de esta última festividad se perdió al poco tiempo de la expulsión de los jesuitas, razón por la que el cabildo se hizo cargo de costearla, a lo que dedicó en el quinquenio de 1788 a 1792 una media de 141 pesos cada año, cuando el Reglamento imponía un límite de 84 pesos. Menores cantidades se gastaban, también, en otras ceremonias, como las de San Carlos, el Santísimo Sacramento, la Virgen de Guadalupe y el Sagrario de la misma advocación mariana cada Jueves Santo. La primera se trataba, en realidad, de una tradición impuesta por el visitador Gálvez cuando acudió a la ciudad en 1767, como forma de enfatizar entre el pueblo el concepto de Majestad en la figura del monarca Carlos III. Por su parte, el Santísimo Sacramento era una obligación cada 29 de noviembre fijada en las Leyes de Indias para todas las poblaciones del reino, 
Economía municipal en el Guanajuato de las reformas borbónicas... - J.L. Caño

mientras que la decoración del Sagrario de la Virgen de Guadalupe cada Jueves Santo era, sencillamente, un añadido al decoro de la Semana Santa en el que el principal gasto era la cera de las velas. Un gasto el último, por cierto, no contemplado en la autorización reglamentada. Por último, mención aparte merecía la celebración de la patrona de la Nueva España, a la que Guanajuato se adhirió en 1737. En este caso, la cantidad era algo mayor, 100 pesos al año autorizados por súplica especial que hizo el ayuntamiento guanajuatense, pero que tampoco representaba un coste tan elevado como el del Corpus Christi o el patrón local.

En otro orden de pagos, que también ayudaban al mantenimiento de las instituciones religiosas, se encontraban las limosnas. Se concentraban éstas en cinco destinos fundamentales, como lo eran el convento franciscano de la localidad, el hospicio y colegio de la orden de Belén y, he aquí lo llamativo, a tres instituciones ubicadas en la ciudad de México y no en la propia Guanajuato, como lo eran los hospicios de San Lázaro, de San Hipólito y la Academia de Artes de San Carlos, con significativas cantidades de 600 pesos anuales a la primera y 200 pesos cada año para cada una de las otras dos. En el caso de las limosnas locales, como la donada a los franciscanos, tenía su lógica y origen en el hecho de que fue San Pedro de Alcántara el primer patrón de la localidad desde que así lo instaurara el obispo Aguiar y Seijas a fines del siglo XVII y hasta la proclamación de San Ignacio como patrón en 1724. Un patronazgo que se decidió mantener y se aprobó formalmente a favor de este convento en 1755, con 100 pesos anuales. Aún más antigua y acostumbrada era la ayuda dada al hospital, hospicio y colegio betlehemita, una orden presente en la población desde su llegada en $1727 .{ }^{11}$ Esta donación sufrió distintos avatares, experimentando una evolución a la baja hasta principios del siglo XVIII, pues pasó de 300 pesos en sus inicios a 100 pesos anuales en 1729, para después volver a aumentarse progresivamente hasta recuperar los 300 pesos al año autorizados por el Reglamento de 1770. Ahora bien, este aumento producido a lo largo del siglo XVIII, especialmente el de 200 pesos en 1741, debe situarse dentro del inicio de unas políticas concretas bien diferenciadas, pues se excusó el mayor estipendio por su específico destino al mantenimiento del hospital y de la escuela, y no tanto al de la iglesia de la orden.

En el caso de las limosnas destinadas a la ciudad de México, éstas se justificaban por el frecuente envío de enfermos que se hacía desde Guanajuato al hospital de San Hipólito, lo que motivó que en 1776 se dictara la orden de ayudar con 200 pesos cada año. En el caso del hospital de San Lázaro fue una imposición de Gálvez, que ordenó la entrega también de otros 200 pesos en 1785, a lo que el virrey decidió añadir otros 400 más en 1787, extraídos del nuevo impuesto. Una fuerte cantidad de la que se quejaba amargamente el cabildo guanajuatense, argumentando que ese

11 Poder para solicitar permiso de fundación de hospital, hospicio y colegio betlehemita, Guanajuato, 23 de junio de 1727. AHUG, PCL, 1727, f. 128. 
impuesto se creó para el sostén de las milicias locales, que ya vimos no eran baratas, y la construcción de infraestructuras muy necesarias para la ciudad.

\section{CONCLUSIONES}

A la vista de todo lo expuesto, se evidencian varios fenómenos de vital importancia para entender la política económica municipal guanajuatense a fines del siglo XVIII. Unos fenómenos que no se limitan únicamente al lustro estudiado, sino que, al contrario, éste sirve para ejemplificarlos y demostrarlos, toda vez que la información aportada también se remonta a la explicación de los orígenes de algunos de los ingresos del ayuntamiento y a la fundamentación de muchos de los gastos permanentes a los que había que hacer frente cada año.

El primer fenómeno que se evidencia es la constante evolución en aumento de los ingresos del ayuntamiento a lo largo de la centuria, derivados del desarrollo sostenido experimentado por la ciudad. Este progreso provenía del propio adelanto de sus minas, cada vez más y mejor explotadas, que actuaban como motor de otras muchas actividades económicas. Actividades no sólo de abastecimiento de insumos y de mano de obra a las propias minas, sino asociadas también al incremento en la capacidad adquisitiva de sus habitantes y al impulso demográfico, tanto por atracción de trabajadores como por crecimiento vegetativo. Lo cual favorecía también el aumento del consumo, principalmente el de alimentos básicos, como los granos y harinas, y de bebidas alcohólicas. Productos de alta demanda sobre los que se aplicaron las nuevas modalidades impositivas, tanto por introducción y almacenaje en el potente sistema de alhondigaje del que disfrutaba Guanajuato, como con la sisa, gravamen específico a vinos y aguardientes.

El segundo fenómeno, posible gracias al anterior, fue el de la ampliación constante también de los desembolsos municipales. Unos dispendios que permitieron el acomodo de la ciudad a las nuevas realidades y tendencias de su tiempo, situándola entre todas aquellas del mundo que pudieron adoptar las políticas de gasto derivadas del mayor interés en la salud e higiene públicas, la extensión de los servicios sociales municipales, el auge y mejora de infraestructuras urbanas, la contribución del municipio a la Corona, la obtención de mayores competencias, mercedes y privilegios que aumentaban sus libertades y posibilidades de actuación, así como de la implantación de cuerpos e instituciones del Estado que facilitaban, a su vez, el aumento de las inversiones en la ciudad y su desarrollo económico, político y social. Buen ejemplo de todo ello lo representa la instalación de cuerpos militares en la población.

Un desarrollo que, en conjunto, permitió incluso obtener un fuerte superávit en las cuentas municipales, algo poco común no sólo en aquella centuria, sino en la historia general de los municipios del mundo hispánico. Una situación económica que, en definitiva, situaba a Guanajuato como uno de los exponentes más significados 
Economía municipal en el Guanajuato de las reformas borbónicas... - J.L. Caño

de riqueza municipal de las colonias, tanto por lo que invertía en las mejoras de su propio municipio, como por lo que podía colaborar al sostenimiento del imperio.

\section{BIBLIOGRAFÍA}

Almanza Carranza, Ezequiel (2010). Alhóndiga de Granaditas: 200 años de historia. Guanajuato: La Rana.

Bernal, A. M. (1978). Haciendas locales y tierras de propios: funcionalidad económica de los patrimonios municipales (siglos XVI-XIX). Hacienda Pública Española, 55, pp. 285-312.

Bernardo Ares, J. M. (1993). Corrupción política y centralización administrativa: la hacienda de propios en la Córdoba de Carlos II. Córdoba: Universidad de Córdoba.

Bertrand, Michel (2018). Endeudamiento y poder municipal al fin del periodo colonial: el caso de Puebla. En: Michel Bertrand y Zacarías Moutoukias. Cambio institucional y fiscalidad. Mundo hispánico, 1760-1850. Madrid: Casa Velázquez, pp. 141-156.

Blázquez Garbajosa, Adrián (1983). Ensayo de clasificación metodológica de los bienes de propios. En: Actas de las II Jornadas de metodología y didáctica de la Historia. Historia Moderna. Cáceres: Universidad de Extremadura, pp. 147-157.

Caño Ortigosa, José Luis. Cabildo y círculos de poder en Guanajuato (1656-1741) (2011). Sevilla: Universidad de Sevilla, pp. 31-80.

Caño Ortigosa, José Luis (2020). Fuentes primarias para el estudio de las rentas de propios y arbitrios de los municipios indianos.Naveg@mérica, 25, pp. 1-39. DOI: https://doi.org/10.6018/nav.441401

Caño Ortigosa, José Luis y José Luis Lara Valdés (2020). La construcción intelectual del paisaje: el bajío antes del Grito de Dolores. Intelléctus, 19:1, pp. 63-89.

Celaya Nández, Yovana (2014). Impuestos locales en Nueva España: Negociación y obra pública en el ayuntamiento de Veracruz en el siglo XVIII. Espacio, tiempo y forma, 27, pp. 37-59. DOI: https://doi.org/10.5944/etfiv.27.2014.12708

Celaya Nández, Yovana (2016). Las finanzas de las ciudades novohispanas ante el reformismo borbónico. Una propuesta historiográfica. Mélanges, 46-1, pp. 89-97. DOI: https://doi.org/10.4000/mcv.6808

Celaya Nández, Yovana (2017). El gobierno de la fiscalidad local el virrey y la Audiencia en la defensa de sus facultades en materia de propios y arbitrios en el siglo XVIII. En: Juan Francisco Pardo Molero, (coord.), El gobierno de la virtud: política y moral en la Monarquía Hispánica (siglos XVI-XVIII). México: FCE, pp. rqマ_rVo.

Celaya Nández, Yovana (2018). La reforma borbónica en la construcción de la fiscalidad local. Los ayuntamientos novohispanos de Orizaba y Querétaro. En: Michel Bertrand y Zacarías Moutoukias, Cambio institucional y fiscalidad. Mundo hispánico, 1760-1850. Madrid: Casa Velázquez, pp. 157-173. 
Díaz Berrio, Salvador (1972). Apuntes para la historia física de Guanajuato. Historia Mexicana, 86, pp. 221-233.

Ensinck, Óscar Luis (1990). Propios y arbitrios del Cabildo de Buenos Aires, 15801821 (Historia económica de una gran ciudad). Madrid: Instituto de Estudios Fiscales.

Ferrero Migó, R. (1987). La hacienda municipal de Valencia durante el reinado de Carlos V. Valencia: Ayuntamiento de Valencia.

Galindo Montiel, Yolanda (1992). La producción minera en el distrito minero de Guanajuato desde el siglo XVII hasta la época actual. Tesis de Maestría inédita, Universidad de Guanajuato.

García García, C. (1996). La crisis de las haciendas locales. De la reforma administrativa a la reforma fiscal (1743-1845). Valladolid: Junta de Castilla y León.

Giménez Chornet, V. (1995). Política económica i hasenda municipal de la ciutat de Valencia en el segle XVIII. Estudis: Revista de Historia Moderna, 21, pp. 243247.

González Beltrán, Jesús Manuel (1999). Haciendas municipales en la Edad Moderna. Funciones y usos. En: José Manuel de Bernardo Ares y Jesús Manuel González Beltrán (coords.). La administración municipal en la Edad Moderna. Cádiz: Universidad de Cádiz, pp. 19 19 -19 .

Gutiérrez Alonso (1997). Ciudades y monarquía. Las finanzas de los municipios castellanos en los siglos XVI y XVII. En: L. A. Ribot y L. de Rosa (dirs.). Ciudad y mundo urbano en la época moderna. Madrid: Actas Editorial, pp. 187-211.

Hernández Chico, José (1976). Descripción de la ciudad y Real de Minas de Guanajuato, 1788 y Juan Antonio de Riaño, Noticias estadísticas de la provincia de Guanajuato, 1803, ambos en Descripciones económicas regionales de Nueva España. Provincias del centro sudeste y sur, 1766-1827. México: INAH, pp. 31-15.

Hoz García, C. (1988). Las reformas de la hacienda madrileña en la época de Carlos III. En: Carlos III, Madrid y la Ilustración. Contradicciones de un proyecto reformista. Madrid: Siglo XXI, pp. 77-101.

Jáuregui, Luis (1999). La Real Hacienda de Nueva España. Su administración en la época de los intendentes, 1786-1821. México: Universidad Nacional Autónoma de México.

Ladero Quesada, M.A. (1997). Las haciendas concejiles en la Corona de Castilla (una visión de conjunto). en VV.AA. Finanzas y Fiscalidad Municipal. León: Fundación Sánchez Albornoz, pp. 7-71.

López Nevot, A. (1995). La hacienda municipal de Granada (1492-1600). Anuario de Historia del Derecho Español, 65, pp. 749-805.

Martínez Ruiz, José Ignacio (1992). Finanzas municipales y crédito público en la España Moderna la hacienda de la ciudad de Sevilla, 1528-1768. Sevilla: Ayuntamiento de Sevilla. 
Economía municipal en el Guanajuato de las reformas borbónicas... - J.L. Caño

Martínez Ruiz, José Ignacio (2000). Crédito público y deudas municipales en España (siglos XV-XVIII). En: Antonio Miguel Bernal Rodríguez (coord.). Dinero, moneda y crédito en la monarquía hispánica. Madrid: Marcial Pons, pp. 863-877.

Mateos Royo, José Antonio (2003). Propios, arbitrios y comunales: la Hacienda municipal en el Reino de Aragón durante los siglos XVI y XVII. Revista de Historia Economica-Journal of Iberian and Latin American Economic History, 21/1, pp. 51-77. DOI: https://doi.org/10.1017/S021261090001020X

Pardos Marunez, J. A. (1984). Hacienda municipal y constitución de rentas: "censos" y deuda del concejo en Burgos, 1476-1510. Anuario de Historia del Derecho Español, 54, pp. 599-612.

Pozas Poveda, Lázaro (2011) Ciudades castellanas y monarquía hispánica. Córdoba: Universidad de Córdoba.

Quintana Toret, F.J. (1989). Endeudamiento municipal, mercado financiero y tesoros en Andalucía. Los censalistas del concejo malagueño (siglos XVI y XVII). Archivo Hispalense, 219, pp. 81-10.

Redondo Veintemillas, G. (1977). El siglo XVII zaragozano: crisis en la hacienda municipal. Estudios, 6, pp. 108-140.

Reza, Alma Linda (2001). Guanajuato ciudad patrimonio. Guía bibliográfica y documental para una historia urbana y arquitectónica. Guadalajara: Instituto de Investigaciones sobre Centros Históricos y Patrimonio Cultural, A.C., pp. 61-63.

Ruiz Martín, F. (1978). Procedimientos crediticios para la recaudación de los tributos fiscales en las ciudades castellanas durante los siglos XVI y XVII: el caso de Valladolid.En:Otazu,A.(ed.).Dineroy crédito (siglos XVIalXIX). Madrid,pp.37-47.

Salas Ausens, J.A. (1992). Las haciendas concejiles aragonesas en los siglos XVI y XVII, de la euforia a la quiebra. En: J.A. Salas (et. al.). Poder político e instituciones en la España Moderna. Alicante: Instituto de Cultura Juan Gil Albert, pp. 9-66.

Sánchez de Tagle, Esteban (2010). Las reformas del siglo XVIII al gobierno; la ciudad, su hacienda, su policía, su ejército. En: Clara García Ayluardo (ed.). Las reformas borbónicas, 1750-1808. México: FCE, pp. 224-164.

Sánchez de Tagle, Esteban (2014). Del gobierno y su tutela. La reforma a las haciendas locales del siglo XVIII y el cabildo de México. México: INAH.

Sanchez Santiró, Ernest (2013). La Real hacienda de Nueva España y el primer reformismo fiscal de los Borbones (1720-1755). Alcances y contradicciones. México: Instituto Mora.

Sanchez Santiró, Ernest (2015). Constitucionalizar el orden fiscal en Nueva España: de la Ordenanza de Intendentes a la Constitución de Cádiz (1786-1814). Historia mexicana. vol. 65 no.1, pp. 111-165.

Serrano Espinoza, Luis Antonio y Juan Carlos Cornejo Muñoz (1998). De la plata, fantasías. La arquitectura del siglo XVIII en la ciudad de Guanajuato. Guanajuato: Universidad de Guanajuato. 
Suárez Grimón, Vicente J. (2005). La reforma de la hacienda municipal en Canarias en el siglo XVIII: el conflicto en torno al establecimiento de la contaduría de propios y arbitrios. Las Palmas de Gran Canaria: Cabildo de Gran Canaria.

Vargas, Fulgencio (2003). La Alhóndiga de Granaditas: Granaditas y su proceso histórico. Guanajuato: Archivo General del Gobierno del Estado de Guanajuato [edición conmemorativa]. 
